\title{
Strong induction effects during the substorm on 27 August 2001
}

\author{
V. V. Mishin ${ }^{1 *}$, V. M. Mishin ${ }^{1}$, S. B. Lunyushkin ${ }^{1}$, Z. $\mathrm{Pu}^{2}$ and C. Wang ${ }^{3}$
}

\begin{abstract}
We report on strong induction effects notably contributing to the cross polar cap potential drop and the energy balance during the growth and active phases of the substorm on 27 August 2001. The inductance of the magnetosphere is found to be crucial for the energy balance and electrical features of the magnetosphere in the course of the substorm. The inductive response to the switching on and off of the solar wind-magnetosphere generator exceeds the effect of the interplanetary magnetic field (IMF) variation. The induction effects are most apparent during the substorm expansion onset when the rapid growth of the ionospheric conductivity is accompanied by the fast release of the magnetic energy stored in the magnetotail during the growth phase. Using the magnetogram inversion technique, we estimated the magnetospheric inductance and effective ionospheric conductivity during the loading and unloading phases.
\end{abstract}

Keywords: Substorm loading and unloading phases; Electromagnetic induction; Polar cap magnetic flux

\section{Findings}

\section{Introduction}

Various induction effects in magnetospheric physics have long been known. Driven by the rapid variation in ionospheric currents, induction electric fields on the ground produce geomagnetically induced currents (GICs) in man-made long conductor systems. Large GICs can lead to severe electric blackouts, communication outages, and corrosion of oil and gas pipelines, especially during superstorms lasting for several days. Large values of $\mathrm{dB} / \mathrm{dt}$, associated closely with GICs, occur in the regions of westward ionospheric electrojets (Boteler and Pirjola 1998; Vodyannikov et al. 2006; Vanhamäki and Amm 2011; Viljanen and Tanskanen 2011; Zhang et al. 2012). Short-period geomagnetic variations (geomagnetic pulsations) with periods $\tau \leq 100-200 \mathrm{~s}$ change the ionosphere's impedance, lead to the partial penetration of induction electric fields carried by MHD waves, affect the formation of double layers and beams of energetic particles, and reduce the dawn-dusk asymmetry in the distribution of ionospheric currents (Lotko 2004; Takeda 2008; Vanhamäki and Amm 2011). Various aspects

\footnotetext{
* Correspondence: vladm@iszfirk.ru

${ }^{1}$ Institute of Solar-Terrestrial Physics of Siberian Branch of Russian Academy of Sciences, Irkutsk, Russia

Full list of author information is available at the end of the article
}

of the induction effects during substorms have also been discussed (Akasofu 1975; Alfven 1977; Lyatsky 1978; Liu et al. 1988; Shelomentsev et al. 1988; Sanches et al. 1991; Lockwood and Davis 1999; Heikkila et al. 2001; Tang et al. 2010; Gordeev et al. 2011; Siscoe et al. 2012).

The fading of auroral brightness before the substorm expansion onset (EO or breakup) was described in (Mende and Eather 1976; Hughes and Rostoker 1979; Pellinen and Heikkila 1984). Wang et al. (2006) and Liu et al. (2007) attributed this effect to the weakening of energetic particle precipitations in the night oval due to the elongation of the geomagnetic tail and concomitant decrease of the loss cone angle during the growth phase. Baumjohann et al. (1981) described the fading of ionospheric convection and field-aligned currents approximately $10 \mathrm{~min}$ before the onset of the substorm on 6 March 1976. In this paper, we investigate the electromagnetic induction effects, including fading of the ionospheric convection during the growth phase and abrupt intensification at the expansion onset, during the substorm on 27 August 2001.

This event has been already studied (Baker et al. 2002; Li et al. 2003; Eriksson et al. 2004; Blake et al. 2005; Spanswick et al. 2009; Mishin et al. 2012). We complement and expand on the previous results, thoroughly analyzing the role of the induction mechanism. In particular,

\section{它 Springer}


we evaluate the contribution of the induction electric field to the cross polar cap potential drop, the magnetotail's induction and magnetic energy loaded/unloaded during the growth/expansion phase in a 1-h interval, as well as the contribution of the inductive magnetic energy to the total substorm energy. The electromagnetic induction caused by the changing magnetic flux in the geomagnetic tail is found to suffice for the observed weakening and sharp increase of the convection during the growth phase and expansion onset, respectively. During the recovery phase, the magnetic flux was virtually constant at a low level, about the same as that before the substorm. Therefore, the investigation of the recovery phase, though important, was not the purpose of this study.

The results have been obtained from the data of a global network of ground-based magnetometers using the magnetogram inversion technique magnetogram inversion technique (MIT)-ISZF (Mishin 1990), which gives the spatial distributions of equivalent and fieldaligned currents and the electric potential in the highlatitude ionosphere. From the MIT output, we determine the major parameters for a simplified magnetosphereionosphere electrical circuit, i.e., the magnetic flux through the polar cap $\Psi$, the cross polar cap potential drop $U_{\mathrm{PC}}$, and the region $1 \mathrm{FAC}$ intensity. The circuit layout is basically the same as in the well-known schemes (e.g., Alfven 1977; Lyatsky 1978; Kan 1993; Akasofu 2013), where the generator is connected to the plasma sheet and ionosphere in parallel. This allows explaining, in particular, why the high-resistance ionosphere during the growth phase is weakly connected with the low-resistance generator and the magnetosphere. We use only one inductance equivalent to the sum of the inductances of the tail and inner magnetosphere (e.g., Alfvén 1977). The contribution of all possible inductances was considered by Crooker and Siscoe (1983) and Liu et al. (1988). At any rate, a simplified scheme suffices to describe the change of the induction energy during the growth and expansion phases determined from the MIT output.

\section{Database and timing}

We explore magnetic data from 101 ground stations at geomagnetic latitudes $\Phi>40^{\circ}$, including the CANOPUS, INTERMAGNET, GIMA, MACCS, and IMAGE international projects and the networks in the Arctic and Antarctic of the Shafer Institute of Cosmo-physical Research and Aeronomy, RAS, the Arctic and Antarctic Research Institute, and the Danish Meteorological Institute. The solar wind (SW) parameters from ACE and Cluster spacecraft and the AE index from WDC-C2, Kyoto are also used.

By using the MIT (Mishin 1990; Mishin et al. 2011), we obtain 1-min resolution 2D maps of equivalent currents (ECs), field-aligned currents (FACs), and the electric potential $U$ in the ionosphere. These give: (1) the values of the ionospheric cross polar cap (PC) potential drop along the dawn-dusk meridian $U_{\mathrm{PC}}$, (2) the PC area $S$, and (3) the region 1 FAC intensity $I_{R 1}$ at all MLT sectors. Using the PC area, we compute the time series for the variable part of the magnetic flux through the northern tail lobe: $\Psi=\Psi_{0}+\Psi_{1}=B S$. Here $B=0.6 \mathrm{G}, \Psi_{0}$ is the magnetic flux through the "old" $\mathrm{PC}$ before the growth phase, and $\Psi_{1}$ is the variable part of PC flux created by the reconnection process on the dayside magnetopause.

A remark is in order. As in our past papers (e.g., Mishin et al. 2011; 2014), we rely on the Dungey open magnetosphere paradigm (e.g., Dungey 1961; Cowley and Lockwood 1992; Milan et al. 2007). That is, a quasistationary reconnection at the daytime magnetopause leads to the growth of the open magnetic flux in the tail, which is balanced by the reconnection in the distant tail. The abrupt drop of the magnetic flux and the expansionsubstorm onset is considered in terms of the reconnection process in the near tail, which starts in the region of closed magnetic field lines and rapidly propagates into the open tail lobes (Russell 2000; Mishin et al. 2001).

Figure 1 shows the variation of the interplanetary magnetic field (IMF) $B_{\mathrm{Z}}, \mathrm{AE}, U_{\mathrm{PC}}, \Psi_{1}$, and $I_{R 1}$ during the substorm. A sharp southward turning of IMF to the level of $B_{\mathrm{z}}=-(3 \div 5) \mathrm{nT}$ at $\sim 02: 15$ UT instigated the substorm

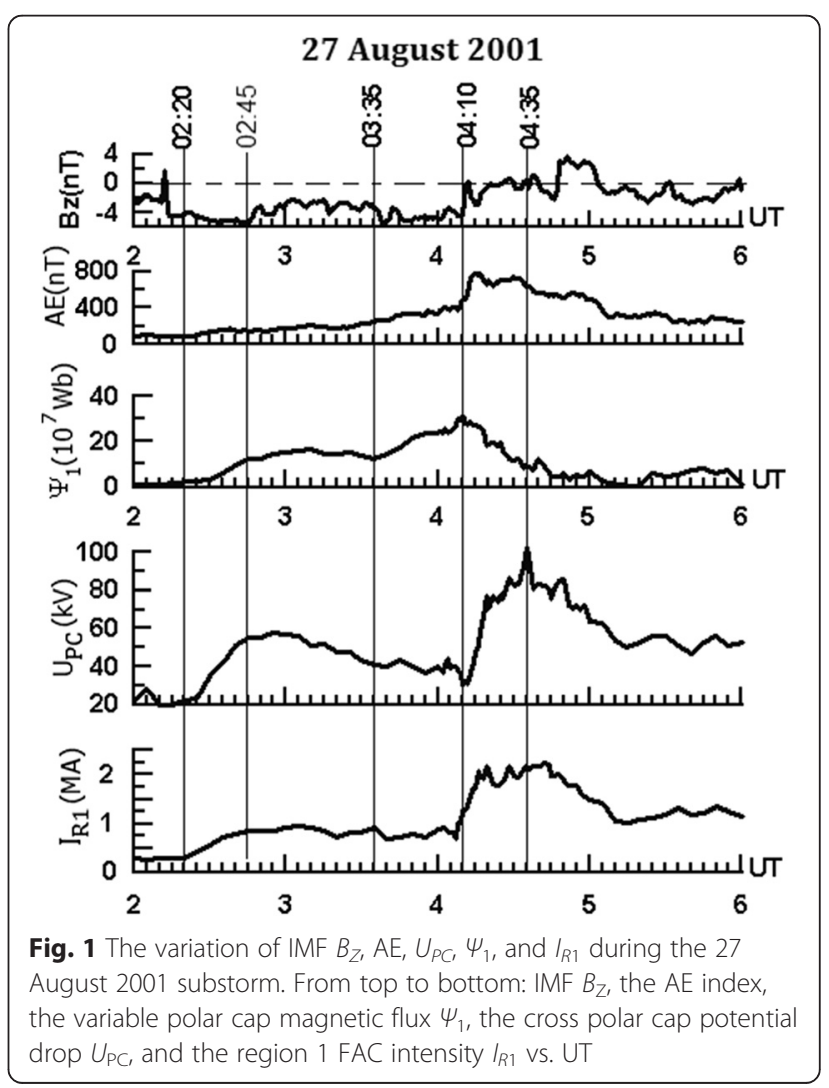


growth phase. At the beginning of the growth phase, $\Psi_{1}$, $U_{\mathrm{PC}}$, and $I_{R 1}$ were increasing synchronously from $\sim 02: 20$ to $02: 45$ UT owing to the switching on of the generator associated with the magnetic reconnection at the magnetopause. However, at 02:45 UT, the growth of $U_{\mathrm{PC}}$ and $I_{R 1}$ slowed down. At $\sim 03: 00 \mathrm{UT}$, the value of $U_{\mathrm{PC}}$ turned to decrease, although the IMF $B_{\mathrm{Z}}<0$ and $I_{R 1} \approx 1 \mathrm{MA}$ remained virtually unchanged. $U_{\mathrm{PC}}$ was decreasing until the first main expansion phase onset (EO1) at 04:08 UT, which was indicated by the fast increase of $I_{\mathrm{R} 1}$. However, $\Psi_{1}$ was increasing until 04:10 UT and then started decreasing. According to Mishin et al. (2001), this indicated the second expansion phase (EO2). Note that $U_{\mathrm{PC}}$ and $I_{\mathrm{R} 1}$ rapidly increased in the period 04:10-04:20 $\mathrm{UT}$. At 04:20 UT, the $U_{\mathrm{PC}}$ growth slowed down, while $I_{\mathrm{R} 1}$ reached the maximum and oscillated around $I_{R 1} \approx 2$. 3MA. At 04:35 UT, $U_{\mathrm{PC}}$ maximized and began decreasing along with AE. Shortly after 05:00 UT, the IMF $B_{\mathrm{z}}$ turned southward again $\left(B_{\mathrm{z}}=-2 \mathrm{nT}\right)$, thereby maintaining a prolonged recovery phase, with $\mathrm{AE} \sim 250 \mathrm{nT}$, $\Psi_{1} \approx 50 \mathrm{MWb}, U_{\mathrm{PC}} \approx 55 \mathrm{kV}$, and $I_{R 1} \approx 1.2 \mathrm{MA}$ until 06:00 UT.

As it follows from Fig. 1, the magnetic flux $\Psi_{1}$ and the ionospheric parameters $U_{\mathrm{PC}}$ and $I_{R 1}$ were increasing during the interval 02:20-03:00 UT. This is typical for the loading phase when the solar wind-magnetosphere generator is switched on by the strengthening southward IMF. During 03:00-04:08 UT, the upward trend in the $\mathrm{AE}$ index and magnetic flux $\Psi_{1}$ (and hence the input electromagnetic energy) persisted. At the same time, the region $1 \mathrm{FAC}$ remained at $I_{R 1} \approx 1.0 \mathrm{MA}$, while $U_{\mathrm{PC}}$ decreased by a factor of two. The decrease of $U_{\mathrm{PC}}$ was likely caused by an increase in the magnetic induction in the course of the growth phase and concomitant growth of the magnetic energy in the geomagnetic tail. The latter was surmised by Akasofu (1975) and Alfvén (1977).

At the beginning of the expansion phase, the induction mechanism markedly affects the unloading of the stored magnetic energy. Indeed, the rapid decrease of $\Psi_{1}$ during 04:10-04:35 UT clearly indicates that the generator at the magnetospheric boundary was switched off. However, $U_{\mathrm{PC}}$ and $I_{R 1}$ increased from 30 to $100 \mathrm{kV}$ and 1 to 2.3 MA, respectively. The dependence $U_{\mathrm{PC}} \propto d \Psi / d t$, which is consistent with the induction effect, during the substorm expansion phase was suggested by Shelomentsev et al. (1988), Gordeev et al. (2011), and Mishin et al. (2012). According to Sandholt et al. (2014), the dipolarization process in substorm expansions could lead to enhancements of the cross polar cap potential by $50-100 \mathrm{kV}$ due to inductive electric fields. The absence of the growth of $I_{R 1}$ until the substorm expansion onset at 04:08 UT implies that the ionospheric load is almost disconnected from the generator in the geomagnetic tail lobes (Akasofu 2013). The sharp increase of $I_{R 1}$ starting at 04:08 UT due to the enhanced ionospheric conductivity relates the onset of the substorm expansion phase with a breakdown in the magnetosphere-ionosphere electrical circuit, i.e., short circuiting of the magnetospheric generator by the ionosphere (Akasofu 1975; Mishin et al. 2013). Thus, inductive effects during the loading (03:35-04:10 UT) and unloading (04:10-04:35 UT) phases facilitate the buildup of the magnetic energy in the magnetotail and its rapid release, respectively. Now, we analyze the two phases in detail.

\section{Energy loading during the growth phase}

The magnetosphere-ionosphere (MI) system has inductance (L) and electrical resistance (R). Various variants of the electric circuit for the MI system including two or more inductors were considered by Lyatsky (1978), Sanchez et al. (1991), Liu et al. (1988), Horton and Doxas (1998), and Ohtani and Uozumi (2014). To illustrate the effects of induction in the magnetosphere, we use a simple RL electric circuit comprising the inductance and resistance of the tail, as well as the effective resistance of the ionosphere.

Let us estimate the inductive energy $\Delta W$ stored in the two magnetotail lobes during the interval 02:4504:10 UT (duration $\Delta t_{1}=5100 \mathrm{~s}$ ) by using the MIT output. Figure 1 shows that after 02:20 UT, the voltage $U_{\mathrm{PC}}$ and the current $I_{R 1}$ were linearly increasing with time until 02:45 UT. The linear dependence indicates that the effective conductivity of the ionosphere (load) $\Sigma_{\text {eff }}=I_{R 1} / U_{\mathrm{PC}}$ remained constant until 02:45 UT. Subsequently, the current remained constant, while the growth of $U_{\mathrm{PC}}$ slowed down and then switched to decay (fading). We assume that such behavior is due to the increase of the inductance, and accordingly the magnetic energy, of the tail. First, we evaluate the voltage $U_{\mathrm{PC}}$ and current $I_{R 1}$ disregarding the accumulation of the magnetic energy in the tail, i.e., without the induction effect.

Figure 2 (left) shows $\Psi_{1}, U_{\mathrm{PC}}$, and $I_{R 1}$ during the growth phase and their linear trends indicated by red solid lines. The red dashed lines present linear extrapolations in the absence of induction. These are obtained by a linear fit of $U_{\mathrm{PC}}$ and $I_{R 1}$ for 02:20-02:45 UT and extrapolated from $t_{0}=02: 45 \mathrm{UT}$ until the end of the growth phase at $t_{\mathrm{EO}}=04: 10 \mathrm{UT}$. As a result, we arrive at

$$
\begin{aligned}
& U_{\text {ext }}(t)=54 \cdot 10^{3}+22.4 \cdot\left(t-t_{0}\right) \mathrm{V} \\
& I_{\text {ext }}(t)=10^{6}+400 \cdot\left(t-t_{0}\right) \mathrm{A}
\end{aligned}
$$

Hereafter, the time difference $t$ - $t_{0}$ (here $t_{0}=02: 45$ UT) is considered in seconds. This leads to the extrapolated value $U_{\text {ext }}\left(t_{\mathrm{EO}}\right)=168 \mathrm{kV}$. On the other hand, the decrease of the observed voltage $U_{\mathrm{PC}}(t)$ from 

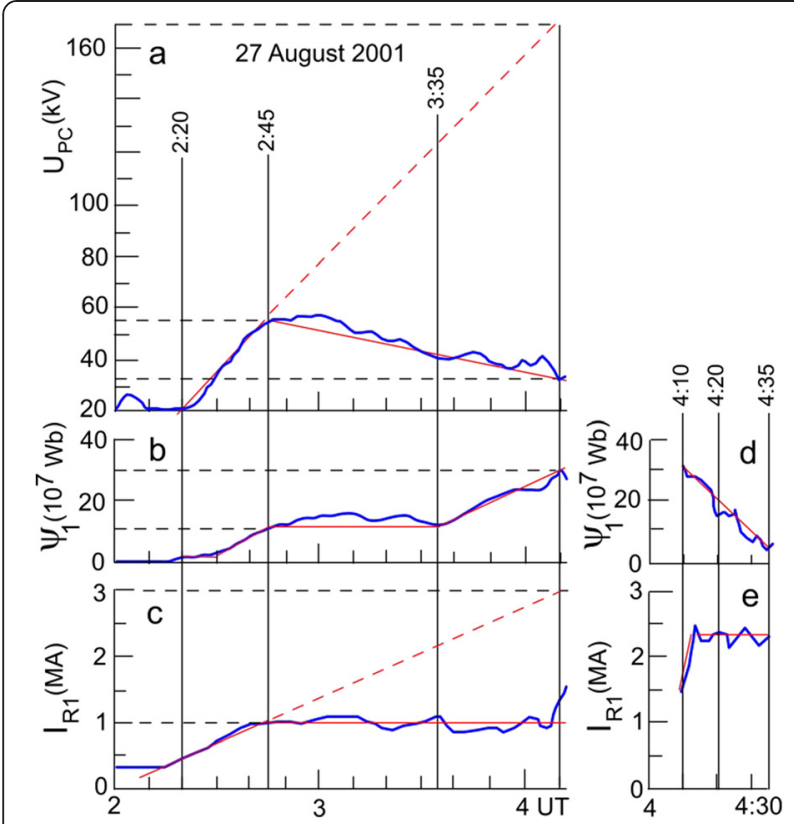

Fig. 2 The variation of $U_{P C}(\mathbf{a}), \psi_{1}$ (b) and $I_{R 1}$ (c) during the loading phase, and $\psi_{1}(\mathbf{d})$ and $I_{R 1}(\mathbf{e})$ during the unloading phase. Red solid lines indicate linear trends. Red dashed lines indicate linear extrapolations in the absence of induction

$U_{\mathrm{PC}}\left(t_{0}\right)=54 \mathrm{kV}$ to $U_{\mathrm{PC}}\left(t_{\mathrm{EO}}\right)=31 \mathrm{kV}$ is approximated by a linear function as:

$$
U_{\mathrm{PC}}(t)=54 \cdot 10^{3}-4.5 \cdot\left(t-t_{0}\right) \mathrm{V}
$$

The difference between $U_{\mathrm{PC}}(t)$ and $U_{\text {ext }}(t)$ can be attributed to the induced EMF in the magnetotail:

$$
U_{\text {ind }}(t)=U_{\text {ext }}(t)-U_{\mathrm{PC}}(t)=26.9 \cdot\left(t-t_{0}\right) \quad \mathrm{V}
$$

Here, we neglected short-period variations of $U_{\mathrm{PC}}$ during the interval 04:08-04:10 UT, which are near the applicability limit for the quasi-stationary approach of MIT.

In turn, the difference between $I_{\text {ext }}$ and the observed $I_{R 1}(t) \approx 10^{6}$ A during this interval gives the induced magnetotail current increasing with time:

$$
I_{\text {ind }}(t)=400 \cdot\left(t-t_{0}\right) \mathrm{A}
$$

Note that the increase of the magnetotail current during the growth phase, with the southward IMF remaining constant, is consistent with the model of Ohtani and Uozumi (2014). To obtain the value of the magnetic energy stored in the two tail lobes, we integrate the product of the induced current and EMF from $t_{0}$ to $t_{\mathrm{EO}}$ as follows:

$$
\Delta W_{\Delta u}=2 \int_{t_{0}}^{t_{\mathrm{EO}}} I_{\text {ind }}(t) \cdot U_{\text {ind }}(t) d t \approx 9.5 \cdot 10^{14} \mathrm{~J}
$$

assuming the equal contribution of each lobe.
An independent estimate of $\Delta W$ can be obtained by replacing the extrapolated EMF $U_{\text {ind }}(\mathrm{t})(1)$ in the integral (3) by the induced EMF $U_{i}=-d \Psi_{1} / d t$ calculated by means of MIT.

We approximate the variation of $\Psi_{1}(t)$ (Fig. 2b) as constant $\left(1.1 \cdot 10^{8} \mathrm{~Wb}\right)$ from $t_{0}=02: 45 \mathrm{UT}$ to $t_{1}=03: 35$ UT and as a straight line

$$
\Psi_{\text {ext }}^{(1)}(t)=1.1 \cdot 10^{8}+9.5 \cdot 10^{4} \cdot\left(t-t_{1}\right) \mathrm{Wb}
$$

from $t_{1}$ until $t_{\mathrm{EO}}$. Replacing $U_{\text {ind }}(t)$ by $U_{i}=-d \Psi_{\text {ext }} / d t$ and substituting (2) and (4) in (3), we arrive at:

$$
\Delta W_{\Delta \Psi}=2 \int_{t_{1}}^{t_{\mathrm{EO}}} I_{\text {ind }}(t) \frac{d \Psi_{\mathrm{ext}}^{(1)}(t)}{d t} d t \approx 6.5 \cdot 10^{14} \mathrm{~J}
$$

Note that Mishin et al. (2014) evaluated the energy stored during the entire loading phase 02:20-04:10 UT by time-integrating the accumulated power. The latter was calculated as the difference between the power of the Poynting flux transported to the polar cap and the power dissipated in the ionosphere and magnetosphere. The value of this integral $\left(\Delta W_{\text {ind }}^{\text {load }} \approx 9 \cdot 10^{14} \mathrm{~J}\right)$ is close to $\Delta W_{\Delta u}$ (3). Comparing (3) and (5) shows that $\sim 70 \%$ of the stored magnetic energy accumulated in the geomagnetic tail during the last third of the loading phase, i.e., from 03:35 to 04:10 UT.

\section{Unloading of the stored energy during the expansion phase}

Figure 2 (right) shows $\Psi_{1}$ and $\mathrm{I}_{R 1}$ during the expansion phase after a northward turning of the IMF $B_{\mathrm{z}}$, i.e., after the solar wind-magnetosphere generator switching off. The decrease of the magnetic flux from $\Psi_{1 \max }=$ $310 \mathrm{MWb}$ to $\Psi_{1 \text { min }}=80 \mathrm{MWb}$ at $t_{\mathrm{EO}=04: 10 \mathrm{UT} \text { until }}$ $t_{2}=04: 35 \mathrm{UT}$ is approximated by a linear dependence:

$$
\Psi_{\text {ext }}^{(2)}(t)=310-0.15 \cdot\left(t-t_{\mathrm{EO}}\right) \mathrm{MWb}
$$

The unloaded energy can be estimated using the integral

$$
\Delta W_{\Delta \Psi}^{(-)}=2 \int_{t_{\mathrm{EO}}}^{t_{2}} I_{\mathrm{ind}}(t) \frac{d \Psi_{\mathrm{ext}}^{(2)}(t)}{d t} d t
$$

Without the induction effect, $I_{\mathrm{R} 1}$ had to return to the pre-substorm value $I_{\text {ext }}^{\min }=0.2 \mathrm{MA}$. However, the induced EMF $U_{i}=-d \Psi_{1} / d t$ enhances the existing (pre-onset) potential drop in the tail, thereby creating the inductive current that flows toward the ionosphere as the region 1 FAC.

The observed current $I_{R 1}$ started increasing at $t_{\mathrm{EO}}=04: 10$ UT from $1 \mathrm{MA}$ and reached 2.3 MA at 04:14 UT. Subsequent insignificant variations around 2.3 MA continued 
until the end of the integration (expansion phase) interval $t_{2}$. Therefore, the variation of $I_{R 1}$ in the subintervals 04:10-04:14 UT and 04:14-04:35 UT can be described as follows:

$$
\begin{aligned}
& I_{\text {ext }}^{(1)}(t)=10^{6}+5400 \cdot\left(t-t_{\mathrm{EO}}\right) \quad \mathrm{A} \\
& I_{\text {ext }}^{(2)}(t)=2.3 \cdot 10^{6} \mathrm{~A}
\end{aligned}
$$

First, we disregard the details of the increase of $I_{R 1}$ after the generator was switched off and assume that it had instantly risen at $t=t_{\mathrm{EO}}$. Then, the value of the induction current should be equal to the observed one, i.e., $I_{\text {ind }}(t) \leq I_{R 1}(t)=2.3$ MA (10). By substituting 2.3 MA in the $\Delta W_{\Delta \Psi}^{(-)}$integral, we obtain the upper limit for the value of the energy unloaded during the period 04:10-04:35 UT:

$$
\Delta W_{\Delta \Psi}^{(-)}=9.5 \cdot 10^{14} \mathrm{~J}
$$

This estimation is based on a slightly overestimated value of the induction current. Taking into account the fact that the increase of the current (7) occurred in the interval from 04:10 to 04:14 UT, we obtain

$$
\Delta W_{\Delta \Psi}^{(-)}=8 \cdot 10^{14} \mathrm{~J}
$$

The value $\Delta W_{\Delta \Psi}^{(-)}(9)$ is between $\Delta W_{\text {ind }}^{\text {load }} \approx 9.5 \cdot 10^{14} J$ (3) and $\Delta W_{\text {ind }}^{\text {load }}=6.5 \cdot 10^{14} J$ (5), i.e., the energy loaded during the entire loading phase and that loaded during the last third of the loading phase (03:35-04:10 UT), respectively. This suggests that the energy released during the initial period of the expansion phase (04:10-04:35 UT) is accumulated mainly near the end of the loading phase $\left(t_{1} \leq t \leq t_{\mathrm{EO}}\right)$. Therefore, the induction effect allows us to quantitatively explain the observed fading of the cross polar cap potential drop and FAC intensity during the growth phase as well as the rapid energy release at the beginning of the expansion phase.

\section{$U_{P C}$ variation and the induction effect}

We now discuss the decrease of $U_{\mathrm{PC}}$ during the growth phase, its sharp increase at the expansion onset, and their possible connection with the $\Psi_{1}$ variation. Prior works usually noted only a subtle effect, i.e., the shortterm fading of $U_{\mathrm{PC}}$ just before the expansion onset. This effect is also seen in Fig. 1 as an abrupt decrease of $U_{\mathrm{PC}}$ at 04:08 UT immediately before $t_{\mathrm{EO}}$. However, we shall not discuss this 2-min drop in $U_{\mathrm{PC}}$ because MIT has a time resolution of only $1 \mathrm{~min}$. In general, the induction EMF in a tail lobe is generated by the varying magnetic flux penetrating the lobe, $U_{i}=-d \Psi_{1} / d t$. The flux variation comprises the temporal and convective contributions

$$
d \Psi_{1} / d t=\partial \Psi_{1} / \partial t+\left(\overrightarrow{V^{\rightarrow}} \nabla\right) \Psi_{1} \approx \partial \Psi_{1} / \partial t+\left(V_{x} / l\right) \Psi_{1}
$$

where $l$ is the effective length of the tail.

The contribution of the time derivative to the magnetic flux is negligible during the growth phase. The convective derivative $\approx\left(V_{x} / l\right) \Psi_{1}$ describes the accumulation of the magnetic flux in the tail with a slow $(\sim 1 \mathrm{~h})$ timescale. Owing to the limited rate of the magnetic flux transfer $\left(V_{x} \leq V_{s w}\right)$, the convective induction effect is the likely cause of a smooth fading of $U_{\mathrm{PC}}\left(\Delta U_{\mathrm{PC}}=-23 \mathrm{kV}\right)$ seen in Fig. 1. A remark is in order. To quantitatively compare $\Delta U_{\mathrm{PC}}$ with the induced EMF $U_{i}$, one should take into account a spatial decrease of the induction potential $\phi_{\text {ind }} \propto 1 / l$ (Pellinen and Heikkila 1984) and the low efficiency of its transmission into the ionosphere (e.g., Gordeev et al. 2011). Unfortunately, the existing models are incapable to give a rigorous quantitative estimate of the transmission coefficient. Using the "accurate" approximation (4) for $\Psi_{1}$ yields $U_{i} \approx-95 \mathrm{kV}$. On multiplying this value by the transmission coefficient $\sim 0.25$, one obtains $-24 \mathrm{kV}$, which is close to $\Delta U_{\mathrm{PC}}$. In the zero approximation for the interval 02:2003:45 UT, the average value of the derivative is $\langle d \Psi / d t\rangle \approx$ 0 . Thus, the main input to the magnetic energy accumulation in the magnetotail (see below) comes from the last third of the growth phase (03:45-04:10 UT).

In contrast, the expansion phase is dominated by the temporal variation resulting in $U_{i} \approx+150 \mathrm{kV}$. This is more than twice the value $\Delta U_{\mathrm{PC}}=+70 \mathrm{kV}$. This difference can be explained by the geometric factor $k$ related with the loop around the tail lobes of the radius $R_{\mathrm{T}}$, where the EMF $U_{i}$ is induced. Figure 3 schematically

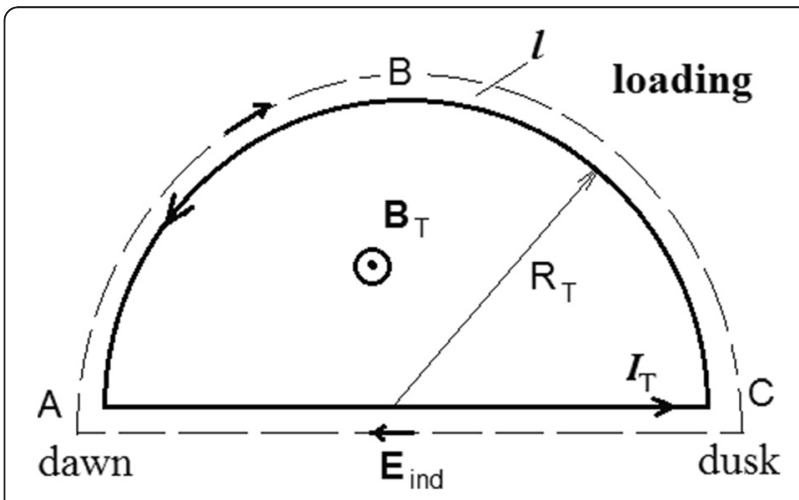

Fig. 3 A schematic of the cross section of the northern lobe during the loading phase. $E_{\text {ind }}$ is the induction electric field, and $I_{T}$ is the dawn-dusk current flowing through the plasma sheet and being closed through the magnetotail boundary. $E_{\text {ind }}$ points to dusk during the unloading phase 
shows the cross section of the northern lobe. The induction EMF is induced in the outer contour by the increasing (the loading phase) or decreasing (unloading) magnetic flux. Here $E_{\text {ind }}$ and $I_{\mathrm{T}}$ are the induction electric field and the dawn-dusk current flowing through the plasma sheet and closed through the magnetotail boundary, respectively. The value of $k$ can be estimated as the ratio of the half circumference $\left(\pi R_{\mathrm{T}}\right)$ of a circle to the perimeter of the semicircle $\left(\pi R_{\mathrm{T}}+2 R_{\mathrm{T}}\right)$, i.e., $k=\pi /(\pi+2) \approx$ 0.6. Physically, it means that a part of the induced EMF is added to the EMF of the solar wind-magnetosphere generator acting in the segment $\pi R_{\mathrm{T}}$ so that the resulting potential difference $-k d \Psi_{1} / d t$ gives $\Delta U_{\mathrm{PC}} \approx 90 \mathrm{kV}$ in the ionosphere.

Note that we do not consider $E_{\text {ind }}$ at the ionosphere level. The induction emf $U_{L}=\int E_{\text {ind }} \cdot d t$ is generated by the magnetic flux variation $(\partial \Psi / \partial \mathrm{t})$ in the tail (circuit $\mathrm{ABC}$, Fig. 3) and is not transferred into the ionosphere. We observed the potential difference $U_{\mathrm{PC}}$ which is the result of the summation in the magnetotail (between points $\mathrm{A}$ and $C$ ) of the potential and vortex electric fields produced by the emf of the generator $\left(\varepsilon_{\mathrm{g}}\right)$ and the induction emf $U_{\mathrm{L}}$ (Fig. 4), respectively. The resulting potential difference $\left(U_{\mathrm{PC}}\right)$ is transmitted onto the ionosphere's load $\left(R_{\text {eff }}\right)$. Figure 3 and the calculation of the coefficient $k$ serve for illustrative purposes, designed to evaluate the limits of integration in $\int E_{\text {ind }} \cdot d l$. If the development of the current disruption begins at the center of the plasma sheet, this coefficient will be less than that at the beginning of the EO and equal to the estimated value only at the end of the current disruption. Its average value is halved.

\section{Estimation of the inductance coefficient}

The MIT data describing the dynamics of the magnetic flux and FAC allow us to also estimate the magnetosphere inductance coefficient $L$ for different substorm phases. Assuming $L$ is a constant, we obtain from the induction law

$$
\left|U_{\text {ind }}\right|=\frac{d \Psi}{d t}=\frac{d(L I)}{d t}=L \frac{d I}{d t}
$$

In general, the contribution of $I \frac{d L}{d t}$ could be comparable with $L \frac{d I}{d t}$. As accounting for the former is quite a formidable problem, we estimate the mean value $\langle L\rangle$ at different moments in the course of the substorm.

We make use of an electric circuit shown in Fig. 4. It includes a generator at the boundary of the magnetosphere, the inductance $L$ of the magnetosphere, and two parallelly connected resistors, indicated as $R_{\mathrm{M}}$ (magnetosphere) and $R_{\text {eff }}$ (ionosphere). The internal resistance $r$ of the generator is small $\left(r<<R_{\text {eff }}\right)$ and thereby can be neglected (Mishin et al. 2011). The inductance of the

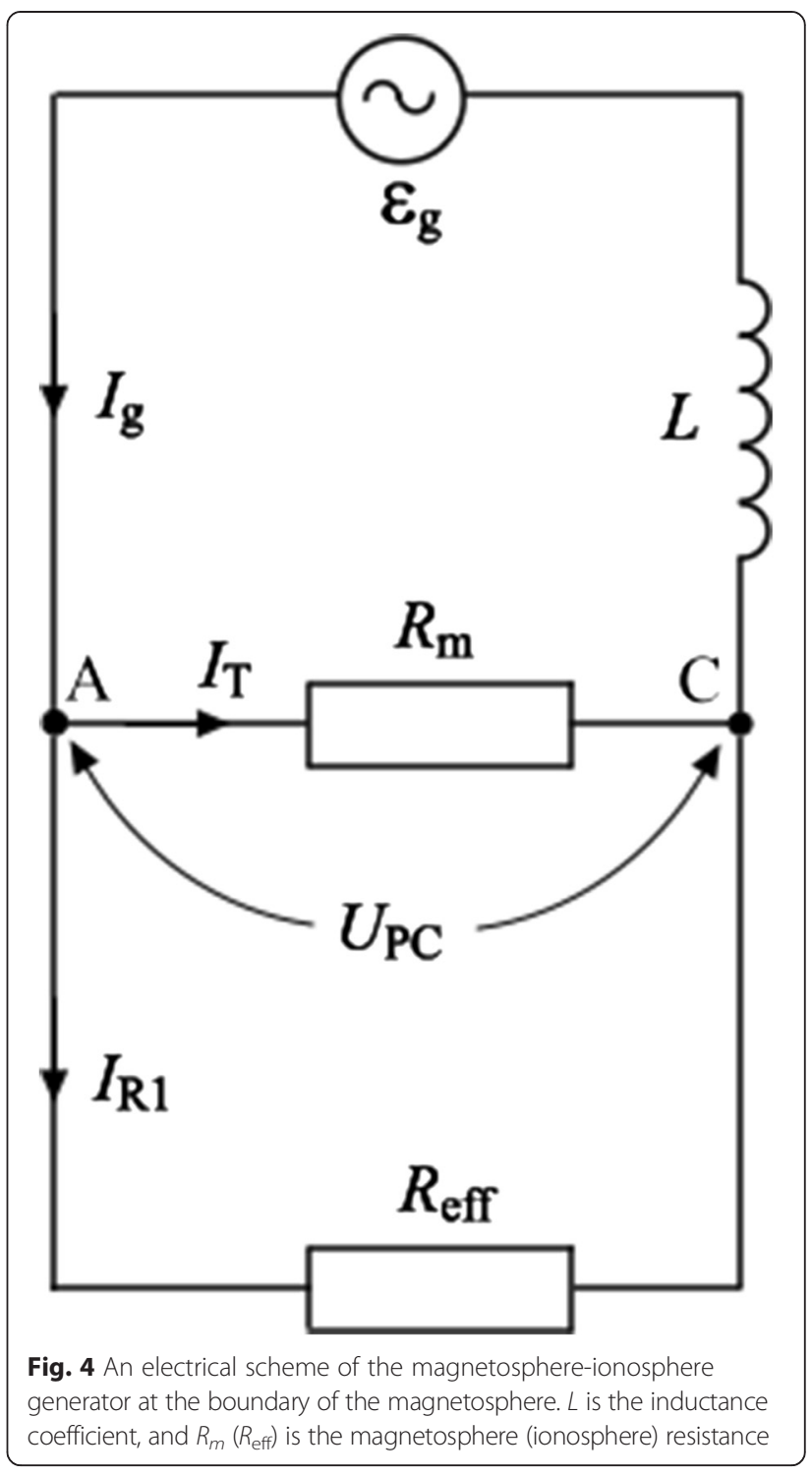

field-aligned currents in the near tail is not taken into account in this scheme. However, note that during the expansion phase, it can reach $L=25$ Hn (Lyatsky 1978). During the growth phase, the resistance in the magnetosphere is small $\left(R_{\mathrm{m}}<<R_{\text {eff }}\right)$. Therefore, the current from the generator, $I g$, only partially flows into the ionosphere closing mainly through the neutral layer of the geomagnetic tail (current $I_{\mathrm{T}}$ ). Its ionospheric fraction is rapidly saturated (interval 02:20-02:45 UT). During the expansion phase, $R_{\text {eff }}$ decreases owing to precipitation of electrons in $\mathrm{R} 1$. In contrast, $R_{\mathrm{m}}$ is anticipated to increase dramatically owing to unstable plasma processes in the tail that ensure the energy release. As an example, we note anomalous resistance in the current disruption region (e.g., Lui 1996). Thus, it is reasonable to suggest that $R_{\text {eff }}<R_{\mathrm{m}}$ and that the current flows mainly through the ionosphere. This conjecture is consistent with the 
theoretical estimates and numerical simulation of the electrical characteristics of the magnetosphere-ionosphere system (Alfvén 1977; Lui 1996; Akasofu 2013).

Using the approximations (2) and (4) during the growth phase $\left(t_{0}-t_{\mathrm{EO}}\right)$ and assuming $L=$ const $=\langle L\rangle$, we obtain from (11) the average value

$$
<L>=d \Psi / d I_{\text {ind }}=240 \mathrm{Hn}
$$

An independent estimate can be obtained by balancing the stored inductive energy $\Delta W_{\Delta u}=9.5 \cdot 10^{14} \mathrm{~J}$ (3) with the loading energy of the two tail lobes

$$
\left.\Delta W_{L}=2<L>\left(I_{\text {ind }}^{2}\left(t_{\mathrm{EO}}\right)-I_{\text {ind }}^{2}\left(t_{0}\right)\right) / 2\right)
$$

with $I_{\text {ind }}\left(t_{\mathrm{EO}}\right)=2.05 \mathrm{MA}$ and $I_{\text {ind }}\left(t_{0}\right)=0$ from (2), we obtain from $(12)<L>=220 \mathrm{Hn}$. Yet another estimate can be obtained using the time dependence of the ionospheric effective resistance $R_{\text {eff }}=U_{\mathrm{PC}} / I_{R 1}$ (Fig. 5) calculated by MIT. It is known that the inductance of a circuit with the active resistance $R$ and the current relaxation time $\Delta t$ is $L=R \Delta t$. During the interval $t_{0}-t_{\mathrm{s}}$ of the duration $\Delta t=3860 \mathrm{~s}$ the average resistance is $\left\langle R_{\text {eff }}\right\rangle=0.052 \Omega$, which gives $\langle L\rangle=200 \mathrm{Hn}$. Therefore, the average inductance of the tail lobes during the loading phase was $\langle L\rangle=200-240 \mathrm{Hn}$.

At the beginning of the expansion phase, Fig. 5 shows a sharp drop of the resistance during the interval 04:0704:14 UT from 0.04 to $0.02 \Omega$ followed by the full recovery at $04: 35 \mathrm{UT}(\Delta t \approx 1200 \mathrm{~s})$. Note that the minimum value of $R_{\text {eff }}$ at 04:14 UT was coincident with the maximum auroral brightness (Baker et al. 2002) and FAC (Mishin et al. 2013). The average resistance for this

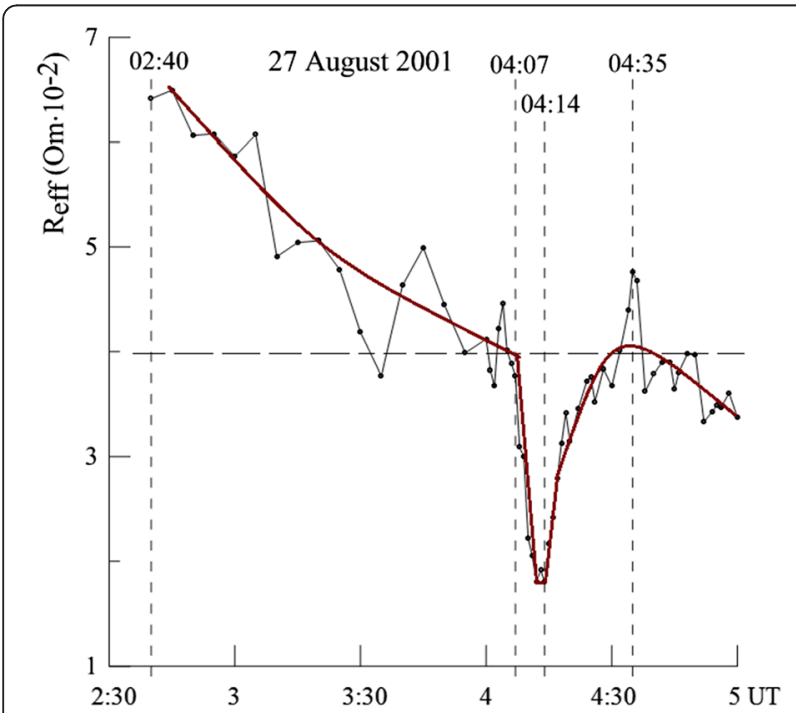

Fig. 5 The effective resistance of the ionosphere. The effective resistance of the ionosphere, $R_{\text {eff }}=U_{P C} / l_{R 1}$, obtained from the 1-min MIT output data. The thick red line shows a smoothed dependence interval was $\left\langle R_{\text {eff }}>\approx 0.03 \Omega(\mathrm{Ohm})\right.$, which corresponds to the average inductance $\langle L\rangle=\left\langle R_{\mathrm{eff}}\right\rangle \Delta t \approx 45 \mathrm{Hn}$. Another estimate of $\langle L\rangle$ can be obtained using the induction law (11) with the variation of the magnetic flux (6) and current (7) during 04: 10-04: 14 UT. This gives $\langle L\rangle=d \Psi / d I_{\text {ind }} \approx 30 \mathrm{Hn}$. These experimental values for the loading and unloading periods are of the same order of magnitude as earlier theoretical estimates (Lyatsky 1978; Alfvén 1977; Liu et al. 1988; Sanchez et al. 1991; Horton and Doxas 1998).

As follows from these estimates, the accumulation of the magnetic flux during the loading phase is associated with the average inductance $\sim 200-240 \mathrm{Hn}$, most likely due to the tail stretching. During the unloading phase, the inductance dropped down to $30-45 \mathrm{Hn}$ because of the tail dipolarization and shortening. The sharp increase of $I_{\mathrm{R} 1}$ was simultaneous with the decrease of the ionospheric resistance (see Figs. 2 and 5). Note that in the initial $8-10 \mathrm{~min}$ of the active phase, the resistance is close to that obtained by Alfvén (1977).

\section{Discussion}

The electromagnetic energy balance in some volume $V$ enclosed by the surface $S$ is defined by

$$
\frac{\partial W_{B}}{\partial t}=\oint_{S}[\overrightarrow{E \rightarrow} \vec{B}] \cdot d \vec{S}-\int_{V} \vec{j} \cdot \vec{E} d V
$$

Usually, in order to analyze the energetics of a substorm, the r.h.s. of the balance Eq. (13) is integrated over the loading and unloading periods. This gives the loaded, $\Delta W_{\text {load }}=W^{*}>0$, and unloaded, $\Delta W_{\text {unload }}=W<0$, energy, respectively. By virtue of the law of energy conservation, it is assumed also that $W^{*}=|W|$ (e.g., Mishin et al. 2014). However, the integral characteristics $W$ and $W^{*}$ help little to describe and understand the induction effects. It is intuitively clear that for fast time variation, the l.h.s. in (13) can be much greater than the r.h.s. Therefore, as noted by Lockwood and Davis (1999), it is necessary to analyze the evolution of the magnetic flux and its time derivative.

The energy accumulated in the tail during the growth phase is released as a result of reconnection (or the cross-tail current disruption) in the near tail and a subsequent formation of the substorm current wedge which results in the auroral substorm in the ionosphere.

In the substorm under study, the rapid increase of the magnetic flux and hence the magnetic energy of the geomagnetic tail occurred during 03:35-04:35 UT. At the end of the growth phase, as shown in Fig. 2, the magnetic energy was increasing, i.e., $\partial W_{B} / \partial t>0$. At the beginning of the active phase, the time derivative became negative, $\partial W_{B} / \partial t<0$, i.e., the energy was being released owing to the Faraday effect (the emergence of the induction EMF). The rapid release after the IMF 
turned to the north and the termination of the Poynting flux transfer explains the observed sharp increase in $U_{\mathrm{PC}}$ and $I_{R 1}$.

Pulkkinen et al. (1998) merely suggested that an impaired decrease of the geomagnetic activity after the external source was switched off (IMF northward turning) could be explained by the continuing energy input due to inductive electric fields $\sim \partial B / \partial t$. In the substorm under study in this paper, the magnetic activity after the northward turning was still increasing (Fig. 1). This was likely caused by the positive feedback in the magnetosphere-ionosphere electric circuit, which enhanced the induction effect. Thus, it appears that the induction effect not only extends the expansion phase but also enhances its development by providing energy for the short circuit regime at the expansion onset (Mishin et al. 2013).

A slow change of the magnetic energy during the loading phase can be understood using the fact that the rate of magnetic flux transfer from the dayside to the tail is limited by the flow velocity $V$ in the magnetosheath. Thereby, the characteristic time $\tau$ of the flux accumulation in the tail of the length $l$ is of the order of $\tau=L / V \approx 1-2 \mathrm{~h}$. The magnetic flux transfer during the loading phase did not increase FACs and the ionospheric currents, since the generator in the tail was virtually disconnected from the low-conductive ionosphere (Akasofu 2013; Mishin et al. 2013). During the expansion onset, the ionospheric conductivity in the pre-midnight ionosphere significantly increased due to electron precipitation. Thereby, the induction current could be closed through the ionosphere via the region 1 current (Mishin et al. 2013). Our initial assumption that the $U_{\mathrm{PC}}$ drop during the loading phase was due to the accumulation of the magnetic energy in the tail is justified by the fact that different methods give close values of the loaded energy.

Finally, we note that the electric field penetration into the parts of the tail lobes and polar cap, which before substorms were passive and did not cause the geomagnetic activity, was enhanced at the beginning of the active phase (Mishin et al. 2014). Indeed, the induction EMF $U_{\text {ind }}=-70 \mathrm{kV}$ is much larger than the observed decrease in voltage $\Delta U_{\mathrm{PC}}=-13 \mathrm{kV}$ in the second half of the loading phase. This is consistent with the earlier results (Pellinen and Heikkila 1984; Gordeev et al. 2011; Sandholt et al. 2014). On the contrary, their values are sufficiently close during the active phase (see the " $U_{\mathrm{PC}}$ variation and the induction effect" section).

It is also worth of note that the numerical estimates obtained in this study are based on three main output parameters of the MIT-ISZF: the total intensity of the R1 FAC $\left(I_{\mathrm{R} 1}\right)$, magnetic flux $\Psi$ through, and potential drop $U_{\mathrm{PC}}$ across the polar cap. These parameters are found by the MIT at the ionosphere's level and specify the integral characteristics of the magnetotail. In this approach, the two generators of different nature, i.e., the solar wind-magnetosphere dynamo (the DD dynamo) and the substorm dynamo (the UL dynamo), are located at the same distance $X$ in the tail and in the same $Y-Z$ plane. In reality, the DD generator is the MHD generator distributed over the midnight magnetotail, whereas the UL generator is located at $X \geq-10 R_{\mathrm{E}}$ and conditioned by non-MHD processes (e.g., Kan 1993; Lui 1996; Akasofu 2003; Lui and Kamide 2003). The different patterns in the development of the plasma convection and ionospheric and field-aligned currents for the DD and UL components during the substorm phases were established by numerical modeling (Kan and Sun 1996). Sun et al. (1998) have performed the mathematical separation of directly driven and unloading components in the ionospheric equivalent currents during substorms using the method of natural orthogonal components.

\section{Conclusion}

Using MIT, we determined the magnetic flux $\Psi_{1}$ through the polar cap during the substorm on 27 August 2001. From its variation, we estimated the magnetic energy stored in the tail during the loading phase and released during the expansion phase. The expansion onset started after the generator at the magnetopause was switched off due to a northward turning of the IMF $B_{Z}$. The energy exchange was most intense during the final $35 \mathrm{~min}$ of the loading phase and initial $25 \mathrm{~min}$ of the unloading phase. The energy released during the initial period of the active phase amounted to about $70 \%$ of the total unloaded energy. Therefore, in order to analyze the power of a substorm, it seems necessary to take into account in the energy balance not only Joule dissipation and Poynting flux but also the time derivative of the magnetic energy, i.e., the effect of the electromagnetic induction.

The drop of $U_{\mathrm{PC}}$ during the loading phase can be qualitatively described as the effect of the accumulation of the magnetic energy transferred from the nose of the magnetosphere in the tail, which does not lead to the growth of FACs and closing currents because of the low ionospheric conductivity.

The electromagnetic induction effect is capable of explaining an unusually strong enhancement of the $I_{R 1}$ FAC and voltage $U_{\mathrm{PC}}$, as well as the short-circuit regime, at the expansion phase onset.

The stretching of the geomagnetic tail during the loading phase leads to the increase of its inductance $L$, while the dipolarization and rapid shortening of the tail during the unloading phase results in the sharp decrease of $L$ and the effective ionospheric resistance $R_{\text {eff. }}$ 


\section{Competing interests}

The authors declare that they have no competing interests.

\section{Authors' contributions}

VMM initiated and directed the study. WM and SL performed data collection and calculation, as well as preparation of drawings and the manuscript. ZP and $\mathrm{CW}$, as all coauthors, have made a significant contribution to the analysis and interpretation of data and reading and approving the final manuscript.

\section{Acknowledgements}

We thank the ISTP SB RAS MIT group members and Dr. E.V. Mishin for stimulating discussions and assistance in translating the manuscript. The Cluster and ACE data sets were obtained through the NASA CDAWeb data service. The AE index was obtained through the website of the World Data Center for Geomagnetism, Kyoto. We are grateful to PIs of the CANOPUS, INTERMAGNET, GIMA, MACCS, IMAGE international projects and of magnetic networks in Arctic and the Antarctic (the Shafer Institute of Cosmo-Physical Research and Aeronomy SB RAS, Arctic and Antarctic Research Institute, and $\mathrm{DMI}$ ), and individual magnetic observatories for providing magnetic data used in this study. WM, VMM, and SBL are supported by the Russian Foundation for Basic Research under grants nos. 13-05-92219, 14-05-91165, and 15-05-05561. Z. Pu is supported by the NSFC grants 41211120176 and 41274167, and C. Wang is supported by the NSFC grant 413111039.

\section{Author details}

${ }^{1}$ Institute of Solar-Terrestrial Physics of Siberian Branch of Russian Academy of Sciences, Irkutsk, Russia. ${ }^{2}$ Peking University, Beijing, China. ${ }^{3}$ State Key Laboratory of Space Weather, Center for Space Science and Applied Research, Chinese Academy of Sciences, Beijing, China.

\section{Received: 19 February 2015 Accepted: 23 September 2015} Published online: 05 October 2015

\section{References}

Akasofu SI (1975) The solar wind-magnetosphere dynamo and the magnetospheric substorm. Planet Space Sci 23(5):817-23. doi:10.1016/00320633(75)90018-5

Akasofu S-I (2003) A source of auroral electrons and the magnetospheric substorm current systems. J Geophys Res 108(A4):8006. doi:10.1029/ 2002ja009547

Akasofu SI (2013) The relationship between the magnetosphere and magnetospheric/auroral substorms. Ann Geophys 31(3):387-94. doi:10.5194/ angeo-31-387-2013

Alfvén H (1977) Electric currents in cosmic plasmas. Rev Geophys 15(3):271-84. doi:10.1029/RG015i003p00271

Baker DN, Peterson WK, Eriksson S, Li X, Blake JB, Burch JL, Daly PW, Dunlop MW, Korth A, Donovan E, Friedel R, Fritz TA, Frey HU, Mende SB, Roeder J, Singer HJ (2002) Timing of magnetic reconnection initiation during a global magnetospheric substorm onset. Geophys Res Lett 29(24):2190. doi:10.1029/ 2002gl015539

Baumjohann W, Mishin VM, Saifudinova TI, Shpynev GB, Bazarshapov AD (1981) Substorms, microsubstorms and disruption of currents in the magnetospheric plasma sheet. Issled Geomagn Aeron Fiz Solntsa 53:182-91

Blake JB, Mueller-Mellin R, Davies JA, Li X, Baker DN (2005) Global observations of energetic electrons around the time of a substorm on 27 August 2001. J Geophys Res 110:A06214. doi:10.1029/2004ja010971

Boteler DH, Pirjola* RJ (1998) The complex-image method for calculating the magnetic and electric fields produced at the surface of the Earth by the auroral electrojet. Geophys J Int 132(1):31-40. doi:10.1046/j.1365246x.1998.00388.x

Cowley SWH, Lockwood M (1992) Excitation and decay of solar-wind driven flows in the magnetosphere-ionosphere system. Ann Geophys 10:103-15

Crooker NU, Siscoe GL (1983) Ring coupling model: Implications for substorm onsets. Geophys Res Lett 10 (8):761-764. doi:10.1029/GL010i008p00761.

Dungey JW (1961) Interplanetary magnetic field and the auroral zones. Phys Rev Lett 6(2):47-8. doi:10.1103/PhysRevLett.6.47

Eriksson S, Øieroset M, Baker DN, Mouikis C, Vaivads A, Dunlop MW, Rème $H_{\text {, }}$ Ergun RE, Balogh A (2004) Walén and slow-mode shock analyses in the near-Earth magnetotail in connection with a substorm onset on 27 August 2001. J Geophys Res 109(A10):A10212. doi:10.1029/2004ja010534
Gordeev El, Sergeev VA, Pulkkinen TI, Palmroth M (2011) Contribution of magnetotail reconnection to the cross-polar cap electric potential drop. J Geophys Res 116(A8):A08219. doi:10.1029/2011JA016609

Heikkila WJ, Chen T, Liu ZX, Pu ZY, Pellinen RJ, Pulkkinen TI (2001) Near Earth current meander (Necm) model of substorms. Space Sci Rev 95(1):399-414. doi:10.1023/A:1005223222128

Horton W, Doxas I (1998) A low-dimensional dynamical model for the solar wind driven geotail-ionosphere system. J Geophys Res 103(A3):4561-72. doi:10.1029/97ja02417

Hughes TJ, Rostoker G (1979) A comprehensive model current system for highlatitude magnetic activity - I. The steady state system. Geophys J R Astron Soc 58(3):525-69. doi:10.1111/j.1365-246X.1979.tb04793.x

Kan JR (1993) A global magnetosphere-ionosphere coupling model of substorms. J Geophys Res 98(A10):17263-75. doi:10.1029/93ja01168

Kan JR, Sun W (1996) Substorm expansion phase caused by an intense localized convection imposed on the ionosphere. J Geophys Res 101(A12):27271-81. doi:10.1029/96ja02426

Li X, Sarris TE, Baker DN, Peterson WK, Singer HJ (2003) Simulation of energetic particle injections associated with a substorm on August 27, 2001. Geophys Res Lett 30(1):1004. doi:10.1029/2002gl015967

Liu ZX, Lee LC, Wei CQ, Akasofu SI (1988) Magnetospheric substorms: an equivalent circuit approach. J Geophys Res 93(A7):7366-75. doi:10.1029/JA093iA07p07366

Liu WW, Donovan EF, Liang J, Voronkov I, Spanswick E, Jayachandran PT, Jackel B, Meurant M (2007) On the equatorward motion and fading of proton aurora during substorm growth phase. J Geophys Res 112(A10):A10217. doi:10.1029/ 2007ja012495

Lockwood M, Davis CJ (1999) The correct application of Poynting's theorem to the time-dependent magnetosphere: reply to Heikkila. Ann Geophys 17(2):178-81. doi:10.1007/s00585-999-0178-2

Lotko W (2004) Inductive magnetosphere-ionosphere coupling. J Atmos Sol Terr Phys 66(15-16):1443-56. doi:10.1016/j.jastp.2004.03.027

Lui ATY (1996) Current disruption in the Earth's magnetosphere: observations and models. J Geophys Res 101(A6):13067-88. doi:10.1029/96ja00079

Lui ATY, Kamide Y (2003) A fresh perspective of the substorm current system and its dynamo. Geophys Res Lett 30(18):1958. doi:10.1029/2003gl017835

Lyatsky WB (1978) Current systems of the magnetosphere-ionosphere disturbances. Nauka, Leningrad, Russia

Mende SB, Eather RH (1976) Monochromatic all-sky observations and auroral precipitation patterns. J Geophys Res 81(22):3771-80. doi:10.1029/ JA081i022p03771

Milan SE, Provan G, Hubert B (2007) Magnetic flux transport in the Dungey cycle: a survey of dayside and nightside reconnection rates. J Geophys Res 112(A1):A01209. doi:10.1029/2006ja011642

Mishin VM (1990) The magnetogram inversion technique and some applications. Space Sci Rev 53(1):83-163. doi:10.1007/bf00217429

Mishin VM, Saifudinova T, Bazarzhapov A, Russell CT, Baumjohann W, Nakamura R, Kubyshkina M (2001) Two distinct substorm onsets. J Geophys Res 106(A7):13105-18. doi:10.1029/2000ja900152

Mishin VM, Förster M, Kurikalova MA, Mishin W (2011) The generator system of field-aligned currents during the April 06, 2000, superstorm. Adv Space Res 48(7):1172-83. doi:10.1016/j.asr.2011.05.029

Mishin W, Mishin VM, Lunyushkin SB, Sapronova LA (2012) Voltage fading during the 27.08.2001 substorm. In: Troyan VN, Semenov VS, Kubyshkina MV (eds) Proceedings of the 9th International Conference "Problems of Geocosmos". Saint-Petersburg State University, SPb, Russia, St. Petersburg, Petrodvorets, Russia, pp 327-9

Mishin VM, Pu Z, Mishin W, Lunyushkin SB (2013) Short-circuit in the magnetosphere-ionosphere electric circuit. Geomagn Aeron 53(6):809-11. doi:10.1134/s001679321306008x

Mishin W, Mishin VM, Pu Z, Lunyushkin SB, Sapronova LA, Sukhbaatar U, Baishev DG (2014) Old tail lobes effect on the solar-wind-magnetosphere energy transport for the 27 August 2001 substorm. Adv Space Res 54(12):2540-8. doi:10.1016/j.asr.2014.09.013

Ohtani S, Uozumi T (2014) Nightside magnetospheric current circuit: time constants of the solar wind-magnetosphere coupling. J Geophys Res Space Physics 119(5):3558-72. doi:10.1002/2013ja019680

Pellinen RJ, Heikkila WJ (1984) Inductive electric fields in the magnetotail and their relation to auroral and substorm phenomena. Space Sci Rev 37(1-2):1-61. doi:10.1007/bf00213957

Pulkkinen TI, Baker DN, Frank LA, Sigwarth JB, Opgenoorth HJ, Greenwald R, Friis-Christensen E, Mukai T, Nakamura R, Singer H, Reeves GD, Lester M 
(1998) Two substorm intensifications compared: onset, expansion, and global consequences. J Geophys Res 103(A1):15-27. doi:10.1029/97ja01985

Russell CT (2000) How northward turnings of the IMF can lead to substorm expansion onsets. Geophys Res Lett 27(20):3257-9. doi:10.1029/2000gl011910

Sanchez ER, Siscoe GL, Meng Cl (1991) Inductive attenuation of the transpolar voltage. Geophys Res Lett 18((7):1173-6. doi:10.1029/91gl01155

Sandholt PE, Farrugia CJ, Denig WF (2014) M-I coupling across the auroral oval at dusk and midnight: repetitive substorm activity driven by interplanetary coronal mass ejections (CMEs). Ann Geophys 32(4):333-51. doi:10.5194/ angeo-32-333-2014

Shelomentsev W, Mishin VM, Lunyushkin SB, Saifudinova TI, Shirapov DS (1988) Substorm electric field dynamics as deduced from ground diagnostic data. Issled Geomagn Aeron Fiz Solntsa 82:170-90

Siscoe GL, Love JJ, Gannon JL (2012) Problem of the Love-Gannon relation between the asymmetric disturbance field and Dst. J Geophys Res 117(A9):A09216. doi:10.1029/2012ja017879

Spanswick E, Donovan E, Liu W, Liang J, Blake JB, Reeves G, Friedel R, Jackel B, Cully C, Weatherwax A (2009) Global observations of substorm injection region evolution: 27 August 2001. Ann Geophys 27(5):2019-25. doi:10.5194/ angeo-27-2019-2009

Sun W, Xu WY, Akasofu SI (1998) Mathematical separation of directly driven and unloading components in the ionospheric equivalent currents during substorms. J Geophys Res 103(A6):11695-700. doi:10.1029/97ja03458

Takeda M (2008) Effects of the induction electric field on ionospheric current systems driven by field-aligned currents of magnetospheric origin. J Geophys Res 113(A1):A01306. doi:10.1029/2007ja012662

Tang CL, Angelopoulos V, Runov A, Russell CT, Frey H, Glassmeier KH, Fornacon KH, Li ZY (2010) Precursor activation and substorm expansion associated with observations of a dipolarization front by Thermal Emission Imaging System (THEMIS). J Geophys Res 115(A7):A07215. doi:10.1029/2009ja014879

Vanhamäki H, Amm O (2011) Analysis of ionospheric electrodynamic parameters on mesoscales - a review of selected techniques using data from groundbased observation networks and satellites. Ann Geophys 29(3):467-91. doi:10.5194/angeo-29-467-2011

Viljanen A, Tanskanen E (2011) Climatology of rapid geomagnetic variations at high latitudes over two solar cycles. Ann Geophys 29(10):1783-92. doi:10.5194/angeo-29-1783-2011

Vodyannikov W, Gordienko GI, Nechaev SA, Sokolova OI, Khomutov SY, Yakovets AF (2006) Geomagnetically induced currents in power lines according to data on geomagnetic variations. Geomagn Aeron 46(6):809-13. doi:10.1134/ s0016793206060168

Wang $H$, Ma SY, Lühr $H$, Liu ZX, Pu ZY, Escoubet CP, Frey HU, Réme $H$, Ritter P (2006) Global manifestations of a substorm onset observed by a multi-satellite and ground station network. Ann Geophys 24(12):3491-6. doi:10.5194/angeo-24-3491-2006

Zhang JJ, Wang C, Tang BB (2012) Modeling geomagnetically induced electric field and currents by combining a global MHD model with a local one-dimensional method. Space Weather 10(5):S05005. doi:10.1029/ 2012sw000772

\section{Submit your manuscript to a SpringerOpen ${ }^{\circ}$ journal and benefit from:}

- Convenient online submission

- Rigorous peer review

- Immediate publication on acceptance

- Open access: articles freely available online

- High visibility within the field

- Retaining the copyright to your article

Submit your next manuscript at $>$ springeropen.com 